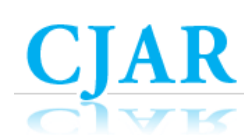

Canadian Journal of Action Research

Volume 21, Issue 1, 2020, pages 27-45

\title{
KNOWLEDGE DEMOCRACY AND EPISTEMIC IN/JUSTICE: REFLECTIONS ON A CONVERSATION
}

\author{
Budd L. Hall \\ University of Victoria \\ Baptiste Godrie \\ CREMIS, Montreal \\ Isabel Heck \\ Parole D'excluEs, Montreal
}

\begin{abstract}
The focus of the article is on how knowledge is created, who creates knowledge, how knowledge is co-constructed, whose knowledge is excluded and how knowledge is being used to challenge inequalities and strengthen social movement capacity. This article grew from a fascinating conversation that the three of us had in Montreal in September of 2019. We decided to share our stories about knowledge and justice with a wider audience in part as a way for us to reflect further on the meaning of our initial conversation, but also to invite others into the discussion. Baptiste Godrie works in a research centre (CREMIS) affiliated with Quebec's health care and social services system, Isabel Heck works with the anti-poverty organization Parole d'excluEs, both affiliated to universities, and Budd Hall works at the University of Victoria and is the Co-Chair of the UNESCO Chair in Community-Based research and social responsibility in higher education.
\end{abstract}

KeY Words: Knowledge production; Knowledge democracy; Epistemic (in)justice; Participatory action research

\section{INTRODUCTION}

Discourses of knowledge democracy (Hall \& Tandon, 2017c), knowledge equity (Chan, 2009, 2018), epistemic inequalities (Godrie, 2019a; Godrie \& Dos Santos, 2017), cognitive justice (Piron, 2017), decolonization of knowledge (Santos, 2014) and cognitive 
imperialism related to Indigenous knowledge in North America (Battiste, 2011) are at the centre of contemporary re-examinations about knowledge. How is knowledge created? Who creates knowledge? How is knowledge co-constructed? Whose knowledge is excluded and how is knowledge being used to challenge inequalities and strengthen social movement capacity?

This article is based on a conversation between three people, two of whom are based in Montreal: Isabel Heck from Parole d'excluEs and Baptiste Godrie with CREMIS. Both of these organisations are community-university research partnerships. Budd Hall is the CoChair of the UNESCO Chair in Community-Based Research, a partnership between the University of Victoria and Participatory Research in Asia based in New Delhi, India. Each of us works within a knowledge democracy or an epistemic justice framework. We are sharing our diverse and similar understandings of knowledge democracy and epistemic justice and discussing the implications for practices of participatory research. Our conversation was fascinating as we listened to each other's stories and ideas. We hope that we have been able to capture some of that enjoyment in this article, and that others will feel free to join and broaden this initial conversation.

\section{Who We Are And How/When Did OUR InTERest in Questions OF EPISTEMic JUSTICE Begin?}

Baptiste Godrie: I am a European immigrant who has been living in Quebec for 16 years. As a sociologist, I am studying social inequalities, and epistemic inequalities in particular, that I do not experience daily because of my social status as a white man belonging to an economically privileged minority and holding a $\mathrm{PhD}$ that gives me an instant credibility in my social interactions. This calls for me to stay vigilant in two respects. First of all, in regarding the institutionalization, even the appropriation, by some academics of concepts that have been forged in militant contexts by intellectuals from the South and the North, particularly of women, indigenous people and members of racialized groups. This appropriation erases their local context of production as much as it serves the careers of those who appropriate them, which is a tangible example of epistemic injustice. Secondly, in regarding the privileges associated to my point of view and knowledge as an academic working with people who are experiencing epistemic inequalities. The ambiguities, discomforts and sometimes creative tensions caused by this position as an ally are a driving force and an important source of reflexivity in my work.

As an activist, involved in the student movement during my studies in sociology and philosophy and later in the global justice movement, I felt the need to deepen my understanding of social inequalities. Therefore, I trained in the field of social and epistemic inequalities and participatory methodologies and epistemologies so that my work might contribute to reducing unequal social relationships.

In 2006, I began my intellectual training at the CREMIS, which occupies an off-centered position with respect to the university. It is both an academic research center on social inequalities and a center designated by Quebec's health and social services system to help rethink health care and social services and reduce the social inequalities experienced by social groups receiving these institutional services. The core values of the CREMIS are the complementarity and non-hierarchical relationships of the knowledge held by people 
receiving services, professionals working in public institutions and academic researchers. These values raise a whole set of epistemological, methodological and ethical challenges since we particularly work with marginalized groups of the population located in downtown Montreal (Godrie et al., 2018).

In my first participatory action research project (2007-2008) conducted with two colleagues and a team of social workers and nurses in the field of homelessness, I discovered the Latin American criticisms of positivism in the social sciences. By positivism, I mean an academic posture of exteriority in relation to the research object and a set of research practices carried out to extract and decontextualize the knowledge and worldviews produced locally by a variety of actors (Escobar, 2018; Godrie \& Dos Santos, 2017). From the very beginning, research appeared to me as a relational work with different people occupying a whole range of knowledge and worldviews that are essential to create a better understanding of a situation (Reiter, 2018). This relational work therefore implicates a social relationship of power during the research process itself and raises questions at the center of my research practice: How can we avoid speaking instead of or on behalf of someone, but instead speak with him or her? How can we collaboratively investigate a reality, taking this plurality of worldviews and knowledge into account, without folding this diversity toward one unique knowledge or worldview?

Over the years, I have been inspired by various research traditions, including: 1) The work of Orlando Fals Borda and his colleagues from La Rosca on participatory and emancipatory research in Colombia; 2) The Institute for Development Studies, including the contribution of Robert Chambers and the participatory rural appraisal approach; 3) The epistemologies of the South (Walter Mignolo, Boaventura de Sousa Santos) and feminist epistemologies (Sandra Harding, Donna Haraway, Nancy Hartsock or Dorothy Smith among others), especially the standpoint theory and the concept of epistemic privilege. Their work criticizes the dominant knowledge practices that render invisible those in subordinate positions, or that reinforce gender and other social hierarchies. Dominant knowledge practices also denigrate subaltern epistemic authority, alternative cognitive styles and other marginalized worldviews and ways of knowledge.

Isabel Heck: As a woman with a mixed European and Middle-Eastern background, I have taken for granted the diversity of values and ways of thinking and living for as long as I can remember. I became used to adapting to norms and hierarchies of different sociocultural contexts, with more or less questioning. Trained in the North American tradition of cultural anthropology in the early 2000s, I have been exposed to the importance of emic, local and indigenous knowledge (Geertz, 1983), and the need for reflexivity of the researchers to situate themselves socially and epistemologically (Ghasarian, 2002). Collaborative research and polyphonic texts (Clifford \& Marcus, 1986), where voices beyond the ones of academics are heard, and the lack of recognition and the confinement of "native anthropology" (Kim 1990; Kuwayama, 2003) were issues linked to epistemic justice and knowledge democracy that intrigued me during my graduate studies. This stirred my interest for alternative ways of knowledge production where excluded voices are heard and valued. 
It is through my involvement as a researcher within an anti-poverty organization in Montreal over the last six years that I came more closely to understand the power dynamics in knowledge production and decision-making, and became engaged in working toward knowledge democracy and epistemic justice. Indeed, Parole d'excluEs is based on the assumption that those experiencing social exclusion and poverty have to be involved in the development of programs and solutions for a more inclusive society. Their analysis, experience and aspirations are not only valuable but necessary to effectively fight poverty and exclusion. The organization, largely inspired by social movements and research traditions from the Global South (in particular the work of Paolo Freire, the Landless Peasant Movement and the Technological Incubator for Popular Cooperatives in Brazil), has developed an action model where citizens, practitioners, managers and researchers come together to codesign innovative projects based on the needs and aspirations of those living in poverty and exclusion. A number of projects have been developed through this model, including an alternative food system, a community-based daycare, transformed urban spaces, artistic productions to reduce discrimination and prejudice, and a community health space.

In these projects, citizens in low-income neighborhoods are recognized as agents who reshape their living environment according to what is important to them, as partners who collaborate with local authorities, and as bearers of knowledge to be considered in decision-making. This model also transforms the role of researchers, as they help to produce knowledge according to what is needed to trigger social and territorial change. Research priorities are identified collectively with actors in the field. Knowledge is produced and mobilized to inspire and orient action, to co-develop projects, models and practice, to systematize and transfer them, as well as to enhance reflexivity (Heck, 2017). Researchers integrate projects horizontally, not as leaders, but as partners with the other stakeholders. We thus work both on concrete projects as well as on methods to democratize knowledge production.

Throughout the years, I have been working closely with the Parole d'excluEs and the CRISES (Center for research on social innovation), both of which have strong traditions of participatory research and co-construction of knowledge with people outside of academia. I have worked with Jean-Marc Fontan in directing a university incubator affiliated with the CRISES. I have also engaged in a north-south dialogue with Marlei Pozzebon and Sonia Tello Rozas, and more recently, I have worked with Baptiste Godrie through seminars on epistemic justice at UQAM based on our shared interest for social research outside universities. As a researcher anchored in a community organization, an ongoing dialogue with academics, practitioners and citizens in other settings, locally and internationally, through field trips, workshops and conferences, seems essential to me in order to go beyond the very local context of my work at Parole d'excluEs not only to nourish our practice, but also to contribute to a larger transformation. Over the past years, such conversations have influenced my discourse and practice more than the reading of academic articles to which my access is, for practical reasons, more limited than for researchers based in institutions. 
Budd Hall: I am excited to be part of this conversation. I have written about my early work in Tanzania in several places (Hall, 1975). To engage with both of you in this conversation, let me first share my reflections now looking back some 50 years. Although quite a bit older than you two, I note that we share some common inspirations. I think Isabel said on the telephone that we have all come to our ideas about knowledge and action from the 'outside' of traditional academic discourses. I am a settler Canadian of English heritage. I am an older white straight male whose great grandparents became middle class Canadians in the $19_{\text {th }}$ Century through the illegal acquisition of Halalt First Nations territory on Vancouver Island on the west coast of Canada. I have benefited directly from the taking of this land and am privileged to live and work not far from Halalt First Nations territory on the traditional territory of the Lekwungen speaking people which includes the Esquimalt, Songhees and WSÁNEĆ First Nations whose relationship to the land continues today.

My curiosity about the relationship between knowledge and justice began many years before I came across the discourses of knowledge democracy or epistemic in/justice. It began as a young researcher working for the Institute of Adult Education in Tanzania between 1970 and 1975. While studying in the USA for my PhD at UCLA in the field of International Education and African Studies, I met the Director of the Tanzanian Institute of Adult Education who was on a study tour in the USA. He invited me to apply for a position as a research fellow in the Institute of Adult Education. At the time, my training in research was in the variety of approaches to survey research methodology. It was a competent preparation as a positivist researcher with an emphasis on research design, statistical competence and grounding in the knowledge created by other researchers.

I was the first full-time researcher hired by the Institute of Adult Education. 1970 was officially designated as Adult Education Year by the Government of Tanzania. The late Mwalimu Julius K. Nyerere, an adult educator and President of Tanzania had developed a political ideology based on African community centred values. Labelled as African Socialism by scholars of the day, Ujamaa na Kujitegemea working together in self-reliance put all the women and men of the country at the centre of plans for moving forward. The assumption was that people making their livings as farmers in rural Tanzania had a deep reservoir of experiential knowledge that should be the foundation of future developments. Participation by people in their own learning, health care, agriculture, and business development was being promoted in all sectors of the state.

But what about research? The positivist research approaches that I had been taught placed an emphasis on expert knowledge, on rigour of methodological design within a knowledge framework of what other scholars and experts had said about a specific situation previously. Research questions came from the literature and the mind of the researcher. People were sources of data, responses to questions generated by the research expert. And for me, an expatriate researcher with little experience of any kind, the contradictions between the research discourses that I had been trained in and the Nyerere assumptions about people having rich bodies of knowledge derived from their daily lives began to grow. There was a small group of Tanzanian and expatriate researchers who shared their work and their common concerns about what we began to think of as colonial research approaches including Marja-Liisa Swantz from Finland, Marjorie Mbillinyi, a 
feminist educator, and Yusuf Kassam, an adult educator. In 1971, Paulo Freire, the Brazilian author of Pedagogy of the Oppressed paid his first visit to Tanzania. I was assigned to look after his visit and accompany him on his visits, including a meeting with President Nyerere. Paulo gave a talk to our Institute of Adult Education on the research methods that he had used in the cultural circles in his home in Northeastern Brazil. His ideas closely related to those of Mwalimu Nyerere. His detailed scholarly elaboration of his ideas of conscientization and the inherent capabilities of ordinary people to shape their own futures added external validation our own thinking about participatory research. Over several years, the discourse which was first formally articulated as participatory research emerged (Hall, 1975). The principles of participatory research (PR) at the time were elaborated as:

1. PR involves a whole range of powerless groups of people-exploited, the poor, the oppressed, and the marginal;

2. It involves the full and active participation of the community in the entire research process;

3. The subject of the research originates in the community itself and the problem is defined, analysed and solved by the community;

4. The ultimate goal is the radical transformation of social reality and the improvement of the lives of the people themselves. The beneficiaries of the research are the members of the community;

5. The process of participatory research can create a greater awareness in the people of their own resources and mobilize them for self-reliant development;

6. It is a more scientific method or research in that the participation of the community in the research process facilitates a more accurate and authentic analysis of social reality;

After leaving Tanzania and having spent a year at the Institute of Development Studies in Sussex, I took up a job as a Research Officer with the International Council for Adult Education, located at the time in Toronto. With the support of this council and growing interest around the world from grass roots organizations and social movements, we launched the International Participatory Research Network (IPRN) in 1978. Rajesh Tandon, from India, became the Coordinator of the network, which had active support from Orlando Fals Borda of Colombia, Francisco Vio Grossi of Chile, John Gaventa of the USA and a strong participatory research group in Toronto, led successively by Edward Jackson, Deborah Barndt, Lynda Yanz and Alfred Jean Baptiste. What is important to note is that interest in the approaches to knowledge creation articulated by the IPRN came almost exclusively from community-based organizations, social movements and international development groups.

In 1991, I left the International Council for Adult Education and joined the Adult Education Department in the Ontario Institute for Studies in Education. It was there that I edited the first North American collection of perspectives on participatory research (Brydon-Miller, Hall, Jackson, \& Park, 1993). But aside from being able to teach a course in participatory research, several of my efforts to create a community-university research centre failed. 
During the years between 1993 and 2005, I became discouraged about the capacity of universities to have the humility, interest or ability to think about knowledge creation in the ways that we now call knowledge democracy or epistemic justice. In 2001, I took up the position as Dean of the Faculty of Education at the University of Victoria. I did not imagine that I would find the support that I had been missing over many years for concepts and practices that I now refer to as knowledge democracy. In 2006, the University of Victoria created an Office of Community-Based Research which I was invited to initiate. As a way to build international support for our work at the University of Victoria, we created an international advisory board headed by my long-time colleague Rajesh Tandon of IPRN in India. From the University of Victoria platform, Community-Based Research Canada and the UNESCO Chair in Community-Based Research and Social Responsibility in Higher Education have emerged.

I returned in my thinking about knowledge and justice to epistemology and hope, ideas which were sparked during my years in Tanzania, but which I had set aside in some ways. My intellectual engagement has been sparked in these past 15 years by the movement of community-university engagement that we have witnessed in Canada and other parts of the world, and by the scholars working on issues of knowledge and justice. I have been influenced by Canadian Indigenous scholars including Drs. Lorna Wanosts'a7 Williams, Marie Battiste, Jeff Corntassel and STOLCEŁ John Elliot of Tsartlip First Nation. My 40 years relationship with Wangoola Wangoola Ndawula of Uganda has influenced my thinking through his work on African Indigenous knowledge, as has the work of Catherine OdaraHoppers and C. Ezeyanya. Some of the Western scholars who have influenced me include Darlene Clover, Enrique Dussel, Cristina Esgrigas, Ramon Grosfoguel, David Harvey, Florence Piron, Boaventura de Sousa Santos and Rajesh Tandon. The concept of epistemicide as articulated by de Sousa Santos (2012) is currently an important concept at the centre of my thinking. Epistemicide refers to the historical erasure of non-European knowledge systems that occurred in conjunction with the colonial expansion of Europe beginning in the 16th century. In Canada, epistemicide has occured most powerfully in the context of the cultural genocide resulting from our colonial foundations which attempted to erase Indigenous languages, knowledges and cultures. But epistemicide is also at work, in more nuanced ways in the denial of legitimate knowledge status to youth, women and men living in poverty, with different abilities or other aspects of social stigma, which the work of Isabel and Baptiste illustrates.

\section{What Do We Understand BY THE CONCEPTS OF EPISTEMic JUSTICE OR KNOWLEDGE DEMOCRACY?}

Baptise Godrie: Since 2007, academics have tended to restrict the reflection of Miranda Fricker's (2007) useful theorization and distinction between testimonial and hermeneutical injustices. But as Budd Hall pointed out, the reflection is much older and richer. Consider the critique of the colonization of minds by Frantz Fanon (1952) going back to the 1950s, or many of the contributions in the field of education since the 1970s, such as the sociological theory of social reproduction through educational institutions, or the feminist work of the 1980s mentioned above.

In a broad sense, I define epistemic justice and knowledge democracy as a type of inequality in the access, recognition and production of knowledge, and different forms of 
ignorance (Godrie \& Dos Santos, 2017). These inequalities hinder the development of the full potential of human beings' worldviews and knowledge and contribute to relationships of economic and epistemic oppression. I use the term epistemic inequalities to emphasize the difference in credibility accorded to the worldview and knowledge of social group members depending on their location in the hierarchy of what is considered credible and legitimate knowledge. That is, it is inequality that stems from unequal social relationships between minorities and majorities. In some cases, these inequalities are produced through discriminations, including illegitimate and unfair treatment (i.e. being discrediting or excluded by dominant group members) due to a person's speech or knowledge because they belong to a historically marginalized social group. In other cases, the internalization of these inequalities causes people to exclude themselves from an interaction or minimize their own cognitive potential.

Epistemic inequalities are tied to economic and social inequalities, for example, not being able to afford a quality education, having limited or no access to the Internet or to a library due to geographical remoteness or lack of public services. People in these situations should not be neglected. In practice and research, epistemic, economic and social inequalities are often reinforced: little is known about some topics because there is not adequate funding to investigate them or because some realities are not considered sufficiently interesting by dominant groups. For example, male contraception has not been explored, not because of a lack of technology, but because of the gender inequalities and sexist bias that places the responsibility on women to manage contraception.

I'm particularly interested in the epistemic inequalities of epistemological nature, that is, those related to the hierarchies between knowledge, to unidirectional and humiliating educational models criticized by Paulo Freire (1968) and Jacques Rancière (1987), to the disregard of local and traditional knowledge and worldviews, to epistemic alienation in colonial contexts and to the hegemony of certain regimes of discourse (entrepreneurial, biomedical, etc.) that naturalize and legitimize the existent social order (e.g., the idea that people at the top of the social ladder owe it solely to their own individual intelligence and knowledge).

Not all epistemic differences are perceived as inequalities. I consider them inequalities when they are perceived as injustices by the people who experience them and/or by their allies, and when they give rise to individual and/or collective resistance. That is where participatory research can play a part in helping raise awareness about the type of inequalities, as outlined earlier by Isabel and Budd. In some context, with or without the involvement of researchers, epistemic injustices can lead to resistance either at the level of the individuals or in the form of social struggles, which José Medina (2013) describes as "epistemic resistance". But what is or is not experienced as an injustice does not come from an innate sense of justice. Experiences of injustice are precisely influenced by the social context and, of course, by the epistemic inequalities.

In my work, I study epistemic inequalities in two contexts. First, I study participatory mechanisms and the ideology of participation in terms of power relations between knowledge holders, particularly in the field of mental health (Godrie, 2019b, 2019c). Public 
institutions tend to practice a selective incorporation of testimonies and knowledge from marginalized groups, especially the ones that do not challenge the decision-making monopolies of managers and health professionals. I also study the mechanisms by which people undermine the credibility of their relatives with mental health problems (Godrie \& Rivet, 2020) and the growing presence of peer support workers in mental health institutions. The latter are employed because they have experiential knowledge of mental health problems and do not have diplomas or professional training in social intervention or health care. But their experience of poverty, mental suffering and health care treatments is not recognized as professional experience by these institutions, which emphasize university degrees as the main source of legitimate knowledge. Second, my work focuses on epistemic justice in participatory knowledge production. Universities are one of the places where the hierarchy of knowledge is historically produced and validated. The exclusion of historically marginalized groups from the process of knowledge production and access to results can exacerbate the social and economic violence they already experience (Godrie, 2019a). But the research process can also be a space conducive to questioning and creating of fairer and more egalitarian social relations in the production of knowledge.

Isabel Heck: I relate very much to Baptiste's understanding, although my interpretation of these concepts is informed more by practice than theory. I understand epistemic justice and knowledge democracy broadly as two concepts helping us to work towards more equality in the production, recognition and consumption of knowledge globally (between the global North and the global South) and locally (within a given society). The concept of epistemic justice is used to reveal inequalities seen as discriminating in the perception and recognition of what someone says (information, understanding, concepts) based on the speaker's attributed origin, gender, level of education, professional and social status, age or even health. It draws attention to the fact that, generally, words from people perceived as lower on the social ladder are less valued. I understand knowledge democracy as a much wider concept which can qualify, in a given context, a person's ability to produce, share and consume information and understanding acquired by education or experience. This can refer to scientific production, spread of theories or categories through journals and other outlets, and the ability to influence and participate in decision-making in public policies, as well as having access to knowledge. To achieve epistemic justice and knowledge democracy, knowledge needs to be produced and consumed in a diversity of ways, by people representing different experiences and backgrounds. I consider Florence Piron's work on cognitive justice and open science impressive in this regard (Piron, 2019).

Why is epistemic justice and knowledge democracy important? From an ethical and political point of view, it means a step forward towards equal rights and greater social justice. It can foster empowerment, active citizenship and participation. Scientifically, it helps conserve otherwise lost knowledge and can contribute to the emergence of new paradigms. In a more pragmatic manner, it can lead to more appropriate and effective solutions and can help strengthen social cohesion and bonds.

Budd Hall: I very much appreciate the diverse ways that the three of us speak about knowledge, power, action, justice and so forth. The multiplicity of concepts helps us to get to the heart of what are complex and contextual relationships. Knowledge democracy in the 
way in which Rajesh Tandon and I refer to it is an interrelationship of phenomena. First, it acknowledges the importance of the existence of multiple epistemologies or ways of knowing, such as organic, spiritual and land-based systems, frameworks arising from social movements, and the knowledge of the marginalized or excluded everywhere, or what is sometimes referred to as subaltern knowledge. Second, it affirms that knowledge is both created and represented in multiple forms including text, image, numbers, story, music, drama, poetry, ceremony, meditation and more. Third, and fundamental to our thinking about knowledge democracy, is understanding that knowledge is a powerful tool for taking action in social movements and elsewhere to deepen democracy and to struggle for a fairer and healthier world. And finally, knowledge democracy is about concepts of both openness and protection of ownership of knowledge. We support open access for the sharing of knowledge so that everyone who needs knowledge will have access to it without cost. But we also support the OCAP principles developed by Indigenous communities in Canada. OCAP refers to principles of ownership, control, access, and protection in the context of Indigenous Knowledge. It is important to note that power relations and knowledge authority differs with Indigenous communities as in all communities. But general principles of respect for ownership of Indigenous knowledge emanating from research projects are critical. To my mind, these same principles should be applied to knowledge work with other excluded communities and excluded epistemologies. Knowledge democracy is about intentionally linking values of justice, fairness and action to the process of using knowledge (Hall \& Tandon, 2017c).

\section{Challenges We Have Experienced in Working The Discourses of KNOWLEDGe democracy and EPISTEMIC IN/JUSTICE?}

Isabel Heck: I would like to point out four challenges I have experienced in working within this framework. First, one of the most important and obvious systemic challenges is the lack of institutional and political recognition of more democratic practices linked to the production and dissemination of knowledge. This has a strong impact on available resources and funding, and therefore on the number of people and organizations engaged in it. Despite some innovative research programs (such as SSHRC's former CURA program, its Partnership grants, or the FRQ's Engage pilot program), support for knowledge democracy and epistemic justice are still marginal, locally and globally, inside and outside academia; reaching a critical mass in order to scale their impact is an essential step for a systemic transformation.

Second, opening organizations to bearers of non-dominant knowledge requires adaptation from both sides. Making spaces available for the marginalized and inviting them is rarely enough. Organizations need to adapt their usual ways to produce knowledge, develop projects and make decisions to ensure a full participation. This often means adapting content, language and animation, adjusting timelines and schedules, and also being ready to convene meetings outside of institutional settings. While researchers and facilitators engaged in action research might more easily show such flexibility, organizations and multi-stakeholder groups often face more institutional barriers to such changes.

Closely linked to the previous is the third challenge addressing the importance of listening to the interests of the marginalized bearers of knowledge. Some advocates of participatory 
action research and participatory approaches to decision-making expect continuous participation of the stakeholders. While such a commitment might enrich projects, it does not necessarily align with the interests and priorities of stakeholders. For instance, in a film we co-created with marginalized young adults to fight against the stigmatization of their neighborhood, group members were unable to commit to regular participation. While this was at first difficult to imagine for the artistic project leader, she accepted and worked with their proposition that one of the group members can make decisions in the absence of their peers. Listening to the interests of people and adapting our methods requires flexibility, but reinforces epistemic justice and emancipation.

Finally, while working towards knowledge democracy and epistemic justice we, as actionresearchers and practitioners, are sometimes confronted with an ethical dilemma where we favor some excluded voices over others. What should be done with voices that discriminate others? Through dialogue and conscientization, some of us try to change their views. However, if we introduce a moral criterion on what to listen to and what not (beyond obvious racist and hate discourse), there is a risk to reproduce discrimination between valued and discarded knowledge, which has been the very reason behind epistemic injustice.

Budd Hall: I would divide challenges that I have faced into three broad categories: the struggle for recognition of participatory research within academic circles, institutionalising structures of community-university research partnerships and the decolonisation of the architecture of knowledge. Personally, the period between 1971 and 1989 was characterized by challenges for academic recognition of knowledge gathering practices that were centred on the experiences of persons excluded from leadership in mainstream society. In our case, working in Tanzania, those excluded from 'legitimate' knowledge discourses included women farmers, persons who did not read, and cattle owners and herders. Our early work within the International Participatory Research Network claimed that everyone created knowledge. We recalled Gramsci's words, "All men are intellectuals, but not all men have in society the function of intellectuals" (1971). Our early work on participatory research was taken up by social movements and by many working in the international development sectors. I was personally attacked by some mainstream adult education researchers for my advocacy of participatory research in both print and in some public conferences. In spite of my willingness, I was not given a chance to teach a course in a Canadian University on participatory research until 1989, when the Faculty of Environmental Studies at York University made such an invitation. From 1989 onwards, I have been able to teach participatory research both at the University of Toronto and the University of Victoria, and I have seen teaching of participatory research grow substantially across Canada and in other parts of the world.

The second set of challenges that, to some extent, we are still working through have to do with the creation of structures to facilitate community-university research structures. While in Quebec, the Service Aux Collectivités within UQAM emerged earlier thanks to strong trade union and community movement support, in the rest of Canada similar structures did not emerge until the first decade of the 21st century. In my case, I was invited to become the Director of the Office of Community-Based Research in 2006. But I 
soon realized that our ability to influence the research cultures in our own university as well as other universities depended on similar community university research structures being created across Canada and elsewhere in the world. Co-construction of knowledge needed to be seen as a substantial trend, and not just an accepted practice of a few individual activist scholars. The major study that we undertook to understand challenges to the establishment of community university research structures concluded that the formal creation of such structures was critical to support principles of knowledge democracy and new forms of community-university research partnerships. As someone working outside Quebec, it has seemed to me that there has been greater funding of participatory research from the Quebec government compared to counterpart provincial governments in the rest of Canada. By now, nearly all Canadian the universities have created their own structures for community-university research partnerships. An important networking space for Canada outside of Quebec has been Community-Based Research Canada, the network which promotes CBR and which is responsible for the biannual Community Campus University Expositions (C2UExpo).

The biggest challenge that we currently face from my perspective is the decolonization of the architecture of knowledge. Participatory research, epistemic justice, knowledge democracy, feminist standpoint epistemologies, Indigenous ways of knowing and more are all responses to a colonized architecture of knowledge that is racialized, patriarchal, classist and Euro-centric. While we have certainly made in-roads towards the acceptance of many of our ideas within the academic world, have we really made any fundamental changes to the structures of knowledge either within higher education or within the wider world? It is true that many of us within the academy who have advocated for and carry out participatory research have been able to establish good careers. But what about researchers who work within social movement structures, community organizations or non-governmental organizations?

Baptiste Godrie: I share very much of the views shared by Isabel and Budd. In my opinion, in a democratic society, there is a responsibility from public authorities to support the development of forms of knowledge that have historically been removed from the public space as legitimate. Epistemic justice is a political as well as epistemological ideal that aims at the development and free circulation of socially relevant knowledge throughout the world (Piron, 2017). This ideal supports the emergence and development of ecologies of knowledge defined as non-oppressive ways of articulating the different modes of knowledge (e.g. scientific, practical, poetic, symbolic, etc.) that give space to the plurality of ways of seeing and acting in the world, whether through rational thought or through the body, emotions and narratives (Santos, 2014).

Drawing on the second challenge identified by Isabel, a step in that direction is to open spaces that are usually closed (universities and symposia only reach a small percentage of the population), but without replicating the already existing epistemic inequalities (or, at least, being aware of their existence because I do not think it is possible to erase relationships of power). In an academic symposium on epistemic inequalities in Namur (Belgium) in February 2019, the co-organizers and I decided to open the submissions and audience to practitioners in the field of health and social services and to members of 
community-based organizations. We also offered mobility grants to support the participation of students from the South, and gave financial contributions to compensate for the time, energy and knowledge of people experiencing poverty that were invited. The event was free of charge and we designed the plenary sessions to encourage small group exchanges and collective discussions.

Despite our efforts, some people - even experienced professionals used to speaking out in public - felt they were less listened to than the researchers. I think it is partly because our mind is socially trained to give less credit to ideas when they are expressed in the language of everyday life than when they are expressed in the codes of science (sometimes characterized by authority, reference and name-dropping, abstract thinking and apparent objectivity that leave little or no space for storytelling and emotions). Professionals and members of community-based organizations were more often referring to life stories and narratives, which may be perceived as anecdotes, and therefore as less relevant by the other participants. What I want to illustrate with this example is that if we want a dialogue between the different experiences, testimonies, knowledge and worldviews, it seems to me that we must move away from the seminar or colloquium type of exchange to experiment with more creative ways of interacting, perhaps including narratives and arts, for instance. I would like to experience doing things together (walking, cooking, etc.) rather than just talking together which makes researchers comfortable, but can make other participants feel ill at ease.

On the epistemological level, many concepts and theoretical resources that Isabel, Budd and I mentioned above are useful to understand how inequalities between different modes of knowledge and worldviews came (and still come) into existence and are maintained. But we still have a long road to implement knowledge ecologies: What would it mean, for example, to experiment with non-oppressive ways of articulating the different knowledge and worldviews about health in a hospital? Local participatory action research projects conducted in this direction would be very instructive as well as politically subversive. Regarding this issue, the persistence of the normative framework of science that pushes university researchers towards conservatism/status quo, is another challenge, well described above by Budd. The often long and bumpy road to be hired as a university professor, and then obtain a permanence, hinders the ability of others to question the hierarchies of knowledge and works toward articulating creative ecologies of knowledge.

\section{Practices And AChievements?}

Budd Hall: These various perspectives on knowledge are all reflected however imperfectly in the current focus of the work of Rajesh Tandon and myself. Our current focus is on providing learning opportunities for a new generation of students and community workers to learn how to do community based participatory research or participatory action research. We do this through the Knowledge for Change (K4C) Global Consortium on Training in Community Based Participatory Research. Drawing on principles of participatory research and working within a framework of knowledge democracy, we have created a 21 week training programme that consists of 19 weeks of on-line learning and a two-week intensive face to face residency. Key concepts which we emphasize are: an orientation to ethics and values, understanding power in partnerships, using multiple 
modes of inquiry, Praxis (the balance of theory and practice), and seeing the researcher as a facilitator. The concept of our K4C Consortium is based on support for the emergence of K4C hubs or training structures. Each hub must be a formal partnership between a university or a part of a university and one or more community organisations. Priority based on our mandate as a UNESCO Chair is given to supporting K4C structures in the majority world or the global South and the excluded North. Our course provides training to middle level experienced mentors, and women and men with substantial experience working within in a social justice framework with communities. The mentors are responsible for leading the training of new generations of researchers in the locations where the hubs exist. By the early 2020s, we have trained over 70 mentors who in turn teach in 15 hubs in Canada, Colombia, Cuba, India (2), Indonesia, Ireland, Italy, Malaysia (2), South Africa (2), Tanzania and Uganda. Each hub undertakes a pledge to develop locally relevant training materials in local Mother tongue languages. Also, each hub prioritizes work in line with one or more of the United Nations Sustainable Development Goals.

Baptise Godrie: That the CREMIS still exists after 16 years as a space of experimentation at the interstice of universities, public institutions and community-based organizations! However, maintaining our balance between these universes is exhausting because we constantly have to prove to our academic peers that we produce scientific knowledge, and to our partners in the community that we produce knowledge that supports and enables action. The two pitfalls always lie in wait: on the one hand, being absorbed by a mainstream way of doing research and losing our roots (and sometimes credibility!) into the institutions and the community; on the other hand, being absorbed by top-down and bureaucratized health and social services institutions that tend to be wary toward critical and autonomous research, and participatory research in particular.

I think of my work as contributing to the diversity of tactics we have to rely on to make structural changes in knowledge production: bringing the plurality of knowledge into the universities to transform them into pluriversities (Boidin, Cohen \& Grosfoguel, 2012; Santos, 2012); and acknowledging and supporting the scientific research (especially in the social sciences) already carried out outside universities, in institutional and community practice settings, but that currently lacks proper recognition and legitimacy.

Part of my work as a sociologist is to support the development of critical thinking of nonacademics about scientific knowledge and, in some cases, to involve them in developing scientific knowledge and other forms of knowledge that are socially pertinent. I am now increasingly approached by community-based organizations who want support to conduct their own research projects - I am helping them to get rid of me!

To support the reflection on participatory research and epistemic inequalities, some colleagues and I have been organizing seminars in Montreal since the end of 2017 to elaborate a research program on this topic. In particular, we have developed a selfassessment guide (which is a work in process) to promote the epistemic inequality lens as a systematic analytical framework for questioning participatory research processes. If this type of research is done to have an impact on epistemic inequalities existing between 
participants of the research process or on the epistemic inequalities experienced by socially oppressed group members, we should be able to appreciate the nature of this impact.

Isabel Heck: Our practice and achievements are on quite different levels. I would like to get back to some achievements and changes in the roles of both citizens and researchers participating in the Parole d'excluEs model outlined above. These changes occurred gradually and are still ongoing, with movements back and forth, with people coming on board and others leaving. What seems to remain is a reconfiguration of roles and power, of knowledge production and decision-making in the mindset of many of those who have participated. This means that citizens experiencing poverty and exclusion are part of those who produce knowledge and make decisions, and that researchers engage in action and forms of knowledge mobilization beyond studies per se. Both changes contribute to knowledge democratization and epistemic justice as understood above. Now, how is this done?

Parole d'excluEs together with an organization in social housing establishes itself in a lowincome neighborhood and opens an animated community drop-in where people can get together, socialize and organize. The research team (from a university incubator dedicated to that model) leads a participatory action study blended with ethnographic methods to understand how the residents of the neighborhood perceive their living environment and their priorities for change. The results are then presented and validated in a citizen's assembly and the participants are invited to form a group to take action. It is thus the citizens who decide upon the priorities, not the staff of the organization nor policy-makers. Participatory research here leads to the recognition of challenges important to citizens that may otherwise be kept silent (Heck \& Castonguay, 2015). Once the priorities are identified, the elaboration of action starts. Citizens, supported by a facilitator from Parole d'excluEs, get together in the community drop-in and often work along with practitioners, managers and researchers on projects. Similar to the ATD Quart Monde method (ATD Quart Monde, 2009), the experiential, practical and academic knowledge merge together, complete each other and ensure for both adapted and feasible solutions. Researchers step out of their role where they lead research: they contribute as partners in knowledge mobilization for projects led by Parole d'excluEs and the citizens. For example, they might bring into discussion academic literature of how people have resolved similar problems in other contexts. And when they carry out further studies, these are pragmatic and action-oriented, which places them in a more horizontal position vis-à-vis the other stakeholders. The ongoing presence of researchers in the field and their positionality further contributes to proximity and trust, which reduces the social distance. This reconfiguration illustrates a more egalitarian way of knowledge production, recognition and access to knowledge.

\section{ConCluding REMARKS}

Our conversation illustrates three different ways to work towards knowledge democracy and epistemic justice. Isabel works as a researcher for a social movement anti-poverty organization, Parole d'excluEs, and is directing a university incubator. Baptiste is located in a jointly led community-university research centre. Budd works these days through the UNESCO Chair in Community-Based Research which focuses on providing learning through 
community-university training hubs for young students and community workers to get started in participatory research. Interestingly, we all started our work institutionally speaking on the margins of academia or even outside academia. We note that being located in different parts of the knowledge universe makes a difference to our ways of working, communicating, acting and even writing. We feel that a conversational space where we can share our different ways of working outside of the bounds of what usually constitutes academic discourse is essential.

One of our conversations related to the questions of references. References are of course the standard way that academic conversations are located, placing them in one discursive area or another. But when one takes into account the power of experiential knowledge, the conversations for example where street-involved youth share their knowledge or when people experience diverse issues of mental health, how do we acknowledge these forms of knowledge? Academic referencing privileges those mostly full-time, rich country, predominantly white and disproportionately male persons who have the time and support to write books, produce articles and take part in conferences. If we are looking for a decolonisation of the architecture of knowledge, are there new practices of acknowledging knowledge sources that we need to find? As you have read through our strands of conversation, you will have noticed diverse approaches to referencing. This is intentional.

What about the present climate for the kinds of issues that the three of us raise? Budd has shared his stories of the struggles to achieve recognition for the concepts of participatory research by the academic world. Working in English speaking Canada, he thought that the 'grass was greener' in Quebec because of some connections made in the early days. Baptiste and Isabel, however, feel that the deeper questions about knowledge equity and knowledge democracy are still not as central as they need to be. We all agree that much more open sharing among the knowledge work experiences of activist scholars like us, community workers using knowledge as a tool, and Indigenous knowledge keepers needs to happen across French-speaking and English-speaking Canada, but also much more across the global boundaries that try to keep us apart.

Finally, we would like to invite all of those reading this article to engage in these issues with us. We are contributing to a centuries old conversation about knowledge, life and hope. This movement is growing and we all have a place in moving things forward.

\section{REFERENCES}

ATD Quart Monde. (2009) Le croisement des savoirs et des pratiques. Quand des personnes en situation de pauvreté, des universitaires et des professionnels pensent et se forment ensemble. Les Éditions de l'Atelier Quart Monde.

Battiste, M. (2011). Cognitive imperialism and decolonizing research. In C. Reilly et al. (Eds.), Surveying borders, boundaries and contested spaces (pp. xv-xxviii). Information Age Publishing. 
Boidin, C., Cohen, J., \& Grosfoguel, R. (2012). Introduction: From university to pluriversity: A decolonial approach to the present crisis of Western universities. Human Architecture: Journal of the Sociology of Self-Knowledge, 10(1), 1-6.

Brydon-Miller, M., Hall, B., Jackson, T., \& Park, P. (1993). Voices of change: Participatory research in the US and Canada. Westport, CT: Greenwood.

Chan, L. (2009, May 17). Open access: Promises and challenges of scholarship in the digital age. Academic Matters. https://academicmatters.ca/open-access-promises-andchallenges-of-scholarship-in-the-digital-age/

Chan, L. (2018, December 10). Open access, the global South and the politics of knowledge production and circulation: An open insights interview with Leslie Chan. Open Library of Humanities. https://www.openlibhums.org/news/314/

Clifford, J., \& Marcus, G.E. (1986). Writing culture: The poetics and politics of ethnography. Berkeley, CA: University of California Press.

Escobar, A. (2018). Designs for the pluriverse: Radical interdependence, autonomy, and the making of worlds. Durham, NC: Duke University Press.

Fanon, F. (1952). Peau noire, masques blancs. Paris, France: Le Seuil.

Freire, P. (1968). Pedagogia do oprimido. Rio de Janeiro, Brazil: Paz e Terra.

Fricker, M. (2007). Epistemic injustice. Power and the ethics of knowing, Oxford, UK: Oxford University Press.

Geertz, C. (1983). Local knowledge: Further essays in interpretive anthropology. New York, NY: Basic Books.

Ghasarian, C, (2002). De l'ethnographie à l'anthropologie réflexive: Nouveaux terrains, nouvelles pratiques, nouveaux enjeux. Paris, France: A. Colin.

Godrie, B. (2019a). Vers une production juste et égalitaire des connaissances sur les inégalités sociales. United Nations Research Institute for Social Development, Think Piece Series. Overcoming Inequalities in a Fractured World: Between Elite Power and Social Mobilization. http://www.unrisd.org/OvercomingInequalities-Godrie.

Godrie, B. (2019b). Raconter sa déraison. Émotions, rapports de pouvoir et participation en santé mentale. Sciences Sociales et Santé, 37(1), p. 43-67.

Godrie, B. (2019c). La co-construction des savoirs au croisement de l'épistémologie et des inégalités sociales. In M. Blanc \& M. Bresson (Eds.), Dossier Savoirs savants et savoirs profanes. https://journals.openedition.org/sociologies/11620. 
Godrie, B. \& Dos Santos, M. (2017). Inégalités sociales, production des savoirs et de l'ignorance. Sociologie et Sociétés, XLIX(1), 7-31.

Godrie, B., Ouellet, G., Bastien, R., Bissonnette, S., Gagné, J., Gaudet, L., Gonin, A., Laurin, I., McAll, C., McClure, G., Régimbal, F., René, J.-F., \& Tremblay, M. (2018). Les espaces de participation et la recherche dans le champ des inégalités sociales. Nouvelles Pratiques Sociales, 30(1).

Godrie, B. \& Rivet, C. (2020, to be published). Injustices épistémiques et réduction identitaire: Ce que l'entraide en santé mentale fait à l'identité de malade. Corps, numéro spécial : Mises en récit et corps souffrant.

Gramsci, A. (1971). Selections from the prison notebooks. London, UK: Lawrence and Wishart.

Hall, B. (1975). Participatory research: An approach for change. Convergence, 3(2), 33-42.

Heck, I. (2017). Du soutien à l'action à la recherche et développement. Bilan des activités du volet de recherche interne à Parole d'excluEs 2013 à 2017. Montréal: Parole d'excluEs et Service aux collectivités UQAM. https://sac.uqam.ca/upload/files /Heck_2017_Du_soutien_\%C3\%A0_laction_\%C3\%A0_la_recherche_et_d\%C3\%A9vel oppement_2013-2017.pdf

Heck, I., \& Castonguay, C. (2015). Étude sur les besoins et aspirations des citoyens du NordEst de Montréal-Nord. Cahier de recherches du CRISES. ES1503.

Kim, C.S. (1990). The Role of the Non-Western Anthropologist Reconsidered: Illusion versus Reality. Current Anthropology, 31(2), 196-201.

Kuwayama, T. (2003). 'Natives' as dialogic partners: Some thoughts on native anthropology. Anthropology Today, 19(1).

Medina, J. (2013). The epistemology of resistance: Gender and racial oppression, epistemic injustice, and resistant imaginations. New York, NY: Oxford University Press.

Piron, F. (2017). Méditation haïtienne: Répondre à la violence séparatrice de l'épistémologie positiviste par l'épistémologie du lien. Sociologie et sociétés, 49(1), 33-60.

Piron, F. (2019). Re-politicising action research through a return to singularity and ethics. Paper presented at the ARNA (Action Research Network of the Americas) conference, Montreal, June 2019.

Rancière, J. (1987). Le maître ignorant: cinq leçons sur l'émancipation intellectuelle. Paris, France: Fayard. 
Reiter, B. (2018). Constructing the pluriverse: Geopolitics of knowledge. London, UK: Duke University Press.

Santos, B.D.S. (2012). The university at a crossroads. Human Architecture: Journal of the Sociology of Self-Knowledge, 10(1), 7-16.

Santos, B.D.S. (2014). Epistemologies of the South: Justice Against Epistemicide. Boulder, CO: Paradigm Publisher.

\section{BIOGRAPHICAL Note:}

Budd Hall shares the responsibility of the UNESCO Chair in Community-Based Research with Dr. Rajesh Tandon, founder of Participatory Research in Asia. He is Emeritus Professor of Adult Education and Community Development at the University of Victoria. He has been working on issues of knowledge, learning and justice since the early 1970s. He is also a poet.

Baptiste Godrie is acting scientific director of the CREMIS, and adjunct professor at the Université de Montréal, where he obtained his $\mathrm{PhD}$ in sociology. His research focuses on social inequalities, social participation and production of knowledge. His work is based on the idea that the recognition and production of knowledge are the product of systemic inequalities and oppressions that structure social relations. He also codirects the working group 21 Diversity of knowledge of the French speaking international sociological association (AISLF). Several of the research projects in which he participated and participates currently are based on participatory methodologies with users-patientactivists, health and social services professionals and researchers.

Isabel Heck is an anthropologist based in the anti-poverty organization Parole d'excluEs and an adjunct professor at the University of Quebec in Montreal. She works on the dynamics and challenges of social change, and more particularly on practices to reduce social inequalities. As an action researcher working in close collaboration with practitioners and citizens in low-income neighborhoods in Montreal, she has been involved in a number of community-lead initiatives to create healthy and supportive environments. Isabel Heck also directs a university incubator affiliated with the Center for Research on Social Innovations (CRISES), though which she has developed action-oriented research methods. 